\title{
Masterplano: mediação radical em ambiências de festas online no contexto da pandemia
}

\author{
Masterplano: radical mediation in online party ambiences in the \\ pandemic context
}

Masterplano: mediación radical en ambientes de fiestas online en el contexto de la pandemia

\author{
Natália Moura Pacheco CORTEZ ${ }^{1}$ \\ Sóstenes Reis SIQUEIRA²
}

\begin{abstract}
Resumo
Com a pandemia de COVID-19 e o crescimento de festas em plataformas online, diversas práticas em ambiências da ecologia midiática digital foram configuradas. $\mathrm{O}$ objetivo deste artigo é investigar as redes de mediações estabelecidas nas festas de música eletrônica em plataformas, destacando-se aqui a plataforma francesa Shotgun, que ambienta o trabalho do Masterplano, coletivo artístico de Belo Horizonte, em Minas Gerais. Este estudo se ampara nos conceitos de mediação radical e estudos de plataformização e destaca a festa online Masterplano em Chromakeyla Tour, na plataforma Shotgun, que aconteceu em junho de 2020 como objeto de análise.
\end{abstract}

Palavras-chave: mediação radical; plataforma; música eletrônica; affordances

\begin{abstract}
With COVID-19 pandemic and the growth of parties in online platforms, several practices in digital media ecology ambiences were configured. The purpose of this article is to investigate the networks of mediations established in electronic music parties in platforms, highlighting the french platform Shotgun, which sets the work of Masterplano, an artistic collective from Belo Horizonte/Minas Gerais. This

\footnotetext{
${ }^{1}$ Doutora em Comunicação Social pela Universidade Federal de Minas Gerais (UFMG). Professora adjunta da Faculdade de Jornalismo da Universidade Federal de Outro Preto (UFOP). Integra o grupo de pesquisa Convergência e Jornalismo (ConJor) e o Grupo MediAção - natalia.cortez@ufop.edu.br ORCID: 0000-0001-9608-0241.

${ }^{2}$ Graduado em Jornalismo pela Universidade Federal do Tocantins, especialista em Produção e Crítica Cultural pela PUC Minas e atualmente é mestrando no Programa de Pós-Graduação em Comunicação da Universidade Federal de Ouro Preto (UFOP) e Bolsista CAPES. Integra o grupo de pesquisa Convergência e Jornalismo (ConJor) - sostenes.siqueira@aluno.ufop.edu.br - ORCID: 0000-00032415-7224.
} 
investigation is based in the concepts of radical mediation and platform studies and highlights the Masterplano online party in Chromakeyla Tour, in the Shotgun platform, which took place in June 2020 as an object of analysis.

Keywords: radical mediation; platform; electronic music; affordances

\section{Resumen}

Con la pandemia de COVID-19 y el crecimiento de fiestas en plataformas online, se configuraron varias prácticas en los entornos de la ecología de los medios digitales. El objetivo de este artículo es investigar las redes de mediaciones instauradas en fiestas de música electrónica en plataformas, destacando la plataforma francesa Shotgun, que ambienta el trabajo de Masterplano, un colectivo artístico de Belo Horizonte/Minas Gerais. Esta investigación se sustenta en los conceptos de mediación radical y estudios de plataforma y destaca la fiesta online Masterplano en Chromakeyla Tour, en la plataforma Shotgun, que pasó en Junio de 2020 como objeto de análisis.

Palabras clave: mediación radical; plataforma; música electrónica; affordances

\section{Introdução}

Nos últimos dez anos, o Brasil tem vivido uma efervescência na cena cultural de música eletrônica de pista - MEP3 em diversas capitais do país. O que antes era restrito a espaços privados como clubes, discotecas e festivais, passa, a partir de $2010^{4}$, a acontecer em espaços públicos como ruas, viadutos e também garagens, galpões e campos de futebol. Em Belo Horizonte, Minas Gerais, os movimentos desta nova cena nascem com uma forte influência das ocupações populares e festivas que emergiram e se fortaleceram em junho de 2013, e que também se articulam junto às mobilizações do carnaval de rua. As intervenções visuais e o discurso de empoderamento de mulheres, pessoas negras e LGBTQIA+ são algumas das características que marcam essas manifestações. Conforme Buzatti (2017), o combate ao machismo, à homofobia e à transfobia são elementares na construção social destas festas, que apostam no diálogo aberto sobre a redução de danos gerados nos contextos de violência contra minorias.

\footnotetext{
3 "A MEP pode, em princípio, ser escutada em qualquer lugar. Porém, para além dessa indeterminação de facto, podemos dizer que é a relação do $D J$ com sua pista de dança que determina, de jure, a sua forma efetiva: certos sons tocados pelo $D J$ gerando certos movimentos na pista de dança e vice-versa, sem que se saiba ao certo quem veio antes". (FERREIRA, 2008, p. 14)

4 "Tudo começou no prédio de todas as festas, a Trackers (quem nunca dançou ali bom sujeito não é), no Centro de São Paulo, em 2010. Com um $D J$ bem provocativo e pesquisador no front, Paulo Tessuto, e uma equipe de produtores, performers e residentes que formaram uma família nada convencional, a Capslock começou a ganhar nome fazendo noites memoráveis em vários endereços, muitas delas de graça, e na rua". (ASSEF, 2019)
} 
A partir de 2015, associados a esse contexto político, surgem coletivos artísticos5 e grupos como Masterplano ${ }^{6}, 1010^{7}$ e Mientras Dura ${ }^{8}$, que movimentam a cena cultural na capital mineira, levando música eletrônica de pista, intervenções visuais e performances artísticas para espaços públicos e/ou espaços fora de clubes. Com essa articulação, o calendário cultural da cidade é marcado por eventos semanais como festas, cineclubes, debates e oficinas, onde público, artistas, DJs, produtores culturais e trabalhadores do setor se encontram.

Recorremos à noção de cena musical de Simone Luci Pereira e Oziel Gheirart (2020), definida como conjunto de atividades sociais e culturais "constituído em torno da música, (...) da dança, dos estilos, das modas, das estéticas, dos gostos e das identidades" (PEREIRA; GHEIRART, 2020, p.6), colaborando, desse modo, para a construção de novas lógicas de produção e consumo que, por sua vez, reelaboram a própria vida na cidade. Assume-se que coletivos como esses citados no artigo acabam por modificar a vida cultural destes locais e a própria noção de entretenimento.

O Masterplano, coletivo artístico de Belo Horizonte, é formado por oito artistas e já realizou mais de 50 edições de festas, com uma média de mil pessoas por evento e centenas de artistas, gerando diversos tipos de interação e performances em suas pistas de dança. Em março de 2020, em virtude da pandemia de COVID-19 e da impossibilidade de aglomerações de pessoas, o calendário de encontros presenciais foi interrompido. Com isso, houve um esforço de adaptação desses grupos a esse contexto com o propósito de criar novos espaços de interação para essa comunidade no Facebook, Instagram, Twitch, Zoom e Shotgun. As interações da comunidade, que antes eram ambientadas em espaços como pistas de dança, praças, ruas e plataformas de redes sociais, passam a ser mediadas exclusivamente por plataformas, a exemplo da Shotgun. Interessa-nos compreender como plataformas assim delineiam essas ambiências e como isso pode ser observado a partir da experiência dos usuários e affordances $^{9}$, em especial na Shotgun.

\footnotetext{
5 Entende-se como um coletivo de música eletrônica, grupos de artistas, $D J s$, produtores culturais que realizam festas, eventos com estéticas próprias. "De 2015 para cá, coletivos como Masterplano, 1010 e Mientras Dura vêm ressignificando o 'rolề' com festas que, para além da música, apostam no "façavocê-mesmo", na diversidade, na liberdade de escolha e na ocupação artística da cidade”. (BUZATTI, 2017).

6 Disponível em: www.masterplano.org.

7 Disponível em: https://www.instagram.com/1010.bh/.

8 Disponível em: https://www.mientrasdura.com.br/.

9 "Affordances são as possibilidades que elas oferecem para a ação (...)" (HUTCHBY, 2017, p.7)" ou "o que fazem fazer" pelo modo como os objetos de uma interface convidam o usuário a agir. Embora esse
} 
A Shotgun é uma empresa francesa, que lançou o Disdancing ${ }^{10}$, uma plataforma criada exclusivamente para festas eletrônicas online com uma interface visual para que DJs consigam transmitir seus sets (seleções musicais) e usuários possam explorar suas espacialidades, como banheiros, salas de dança e compartilhamentos de áudio de microfone, imagem de webcam e mensagens de texto. Esta plataforma simula ambientes convencionalmente conhecidos de uma festa eletrônica presencial, em um contexto que só o online é possível.

A partir deste objeto de estudo, espera-se investigar as redes de mediações que ambientam práticas de festas na plataforma Shotgun e como ela reconfigura a experiência na festa, tendo em vista as especificidades das redes de mediação que se estabelecem na transição entre festa presencial e plataforma online. Tendo em vista essa proposta, lança-se mão do conceito de mediação radical, de Richard Grusin (2015), como operador teórico-conceitual. Trata-se de um conceito pertinente para o contexto pandêmico que delineia a atual conjuntura, em que o online "transforma, modula ou perturba relações vividas" (GRUSIN, 2015, p.128) de forma significativa. Espera-se, com esse estudo, compreender as dinâmicas de interação estabelecidas nas festas de música eletrônica mediadas por plataformas, destacando-se aqui a plataforma Shotgun. Para compreender essas redes de mediação, recorremos também ao conceito de affordances para descrever as funções nas interfaces da plataforma bem como os rastros deixados pelos usuários a partir de seu acionamento, constituindo, assim, as ambiências as quais buscamos investigar.

Recorremos aos métodos digitais e à observação participante para coleta e análise de dados. Os rastros das diversas agências que tecem as redes de mediações na Shotgun Disdancing, tais como as interfaces e suas affordances, algoritmos, códigos, sistemas computacionais, usuários das plataformas, artistas, DJs e outros constituem a ambiência da festa. Em razão dessa agregação, fortemente marcada pelo hibridismo e afetação recíproca entre as agências aqui destacadas, adotamos o conceito de mediação vinculado à noção de rede, conforme a Teoria Ator-Rede de Bruno Latour (2012). Assim, antes de caracterizar a mediação como radical (GRUSIN, 2015), destacamos que a mediação se configura pela associação e afetação mútua entre os

conceito tenha origem na Psicologia Gibsoniana, a noção de Hutchby (2017) é aqui acionada em razão de sua adequação ao objeto de análise do artigo.

${ }^{10}$ Disponível em: https://staging.shotgun.live/events/290825/stream. 
actantes, que, na visão da TAR, constituem-se como estado momentâneo delineado pelas ações de diversas entidades nas redes de mediação.

A noção de ator-rede, central na perspectiva da TAR, postula que as entidades se constroem na relação com outras entidades, e não pelos seus atributos inerentes. Como as redes resultam das relações entre actantes, se não há relação tampouco há actante, uma vez que esses conceitos são correlacionados e interdependentes. Portanto, a perspectiva de mediação adotada no âmbito desse artigo é antiessencialista e não-antropocêntrica, tendo em vista o caráter híbrido da ambiência a qual se busca desvelar.

Parte-se de proposta descritiva e exploratória, tendo como base o conceito de mediação radical e em rede para condução da investigação. $\mathrm{O}$ artigo está organizado da seguinte forma: o primeiro tópico aborda o Masterplano e a trajetória do coletivo artístico e sua relação com o contexto de plataformização ${ }^{11}$; o segundo tópico discute a noção de mediação radical como operador teórico conceitual e traz relatos do idealizador e programador da plataforma Shotgun Disdancing; o terceiro tópico apresenta as funcionalidades desta plataforma, a partir de suas affordances; o quarto tópico analisa as redes de mediação e a constituição da ambiência; e o quinto e último tópico faz as considerações finais a partir dos objetivos propostos no artigo.

\section{Masterplano: trajetórias e redes em plataformização}

Em 2015, o arquiteto Vitor Lagoeiro criou um grupo na plataforma Facebook para reunir amigos e organizar um evento denominado "rave doméstica". O evento aconteceria em sua residência, em Ouro Preto, Minas Gerais. Foi denominado "Masterplano" o grupo responsável por organizar o evento, que se ocuparia dos assuntos referentes à festa, como aluguel de equipamentos de som, iluminação básica e contratação de transporte para pessoas irem de Belo Horizonte a Ouro Preto.

Após a "rave doméstica", o grupo de Facebook gradativamente se transformou em uma página e, posteriormente, em um pequeno coletivo artístico. Duas semanas depois, em junho de 2015, o grupo, já denominado Masterplano, realizou uma pequena

\footnotetext{
${ }^{11}$ Plataformização se refere ao modo como diferentes setores ou esferas da vida social são transformados pela emergência das plataformas. Isso ocorre porque as plataformas passam a delinear processos de interação social, modelos de negócios, mecanismos de dataficação e monetização resultantes de relações comunicacionais entre usuários, algoritmos e dados. (VAN DIJCK; POELL; DE WAAL, 2018, p.25)
} 
festa ao ar livre, aberta ao público, no centro de Belo Horizonte, na parte externa do bar Família Miranda, apresentando o coletivo, publicamente, pela primeira vez.

A comunicação do coletivo inclui uma rede de plataformas distintas para circulação de informações composta por Facebook, Instagram, Soundcloud, Telegram e o site (www.masterplano.org). O grupo na plataforma Facebook é voltado para as trocas de referências musicais, divulgação de programação em diferentes cidades e circulação de DJs sets (seleção musical dos DJs). O Soundcloud, plataforma de streaming de música, é um canal de divulgação de $D J$ sets dos artistas do coletivo, o Telegram opera como um canal direto com o público para a divulgação da programação do Masterplano, e o Instagram, por sua vez, como a rede de divulgação de fotografias e vídeos de festas e atividades. Além disso, desde 2017, o coletivo tem um site com divulgação do portfólio, fotos, entrevistas, sets, atendendo a um propósito institucional.

A origem e manutenção da comunidade Masterplano dependem, portanto, em grande parte, das plataformas digitais. Desde 2015, as redes de mediação que viabilizam essa interação acontecem em uma ecologia que envolve chats, grupos de discussão, aplicativos de conversa instantânea, como o Telegram, comentários em sets musicais, conversas em eventos no Facebook, mensagens diretas no Facebook e Instagram, enquetes nos stories do Instagram e uma infinidade de comentários e compartilhamentos em todas essas redes.

Essa rede multiplataforma ajuda a constituir a noção de comunidade, o pertencimento e os laços sociais dessas pessoas/usuários, que são artistas, DJs, produtores de evento, coletivos artísticos de outros lugares do Brasil e do mundo, equipe de segurança, fornecedores de equipamento técnico de som, iluminação e segurança, e público participante das festas. Assim, considera-se que esta comunidade estende suas ações para o contexto de plataformas como forma de viabilizar sua existência em um cenário de pandemia global. Coaduna-se com a perspectiva de Langlois (2014) que considera que plataformas vão além das funções de armazenar grandes quantidades de informações: elas atuam também pelos modos de viabilizar as produções de sentidos nos gigantescos bancos de dados que operam (LANGLOIS, 2014, p.33).

Esses aspectos de armazenamento de dados e produção dos sentidos mediados por plataformas relacionam-se aos processos de dataficação, que, por sua vez, referemse: 
(...) à capacidade de plataformas em rede de transformar em dados muitos aspectos do mundo que nunca foram quantificados antes: não apenas dados demográficos ou de perfil oferecidos por clientes ou solicitados por eles em pesquisas (online), mas metadados comportamentais derivados automaticamente de smartphones (...) (VAN DIJCK; POELL; DE WAAL, 2018, p.37) ${ }^{12}$

A cada nova interação, novos dados são capturados e gerados, novas recomendações são feitas, em um feedback constante de recomendações e personalizações. Os dados são oferecidos a terceiros com finalidades comerciais, e utilizados como expressão da colonialidade do poder (PASQUINELLI; JOLER, 2020). Neste processo, pode-se perceber a manutenção dos grandes conglomerados digitais e a construção de novos aplicativos e plataformas a partir desta apropriação de dados.

Com a expansão desses dados gerados em diversas plataformas, redes de mediação são desenvolvidas em um processo contínuo entre esses grupos, envolvendo plataformas digitais, pistas de dança e usuários. E, como aponta Richard Grusin (2015),

essas novas mídias técnicas não são conceitos secundários, agentes, ou dispositivos que se interpõem ou conectam assuntos e objetos existentes, culturas e naturezas, corpos e ambientes, ou humanos e não-humanos. Em vez disso, como a própria mediação radical, essas novas formações de mídia técnica produzem as mediações através das quais tais oposições, e, mais radicalmente, tais multiplicidades são geradas em contínuo. (GRUISIN, 2015, p.146) ${ }^{13}$.

Nesses contextos, pode-se observar a reconfiguração constante dos laços da comunidade e identidade dos usuários a partir do feedback constante de agências humanas e não-humanas, próprios do contexto de dataficação.

\section{Percorrendo affordances e tecendo redes: mediações híbridas}

Na tentativa de compreender como se dá a mediação nas redes de plataformas na comunidade Masterplano, recorremos à perspectiva de seguir os meios e conhecer

\footnotetext{
${ }^{12}$ No original, em inglês: (...) "datafication" refers to the ability of networked platforms to render into data many aspects of the world that have never been quantified before: not just demographic or profiling data volunteered by customers or solicited from them in (online) surveys but behavioral meta-data automatically derived from smartphones (VAN DIJCK; POELL; DE WAAL, 2018, p.37). ${ }^{13}$ No original, em inglês: (...) these new technical media are not secondary concepts, agents, or apparatuses that come between or connect extant subjects and objects, cultures and natures, bodies and environments, or humans and nonhumans. Rather, like radical mediation itself, these new formations of technical media produce the mediations through which such oppositions, and more radically such multiplicities, are generated in continuous (...) (GRUISIN, 2015, p.146).
} 
as entidades humanas e não-humanas envolvidas nesse processo. Pode-se dizer que há uma rede de interconexões que emergem nesta comunidade, mediadas por relações, afetos, contratos de usuários, protocolos, scripts de programação, algoritmos e outros. Para desvelar essa rede, coaduna-se com a perspectiva de Bruno Latour (2012) da Teoria Ator-Rede que considera que humanos e não-humanos agem de maneira associada, recusando, assim, tanto uma visão antropocêntrica quanto uma visão técnica, mas uma ação complementar das duas. Em uma sociedade de plataformização, os actantes não-humanos são tão importantes quanto os humanos, e é a partir do reconhecimento de sua agência que se busca compreender a articulação das redes de mediação a partir das atividades da Masterplano.

Juntamente aos estudos de plataforma, adota-se como operador teóricoconceitual a noção de mediação radical, que, conforme Richard Grusin (2015), opera como mediação entre coletivos humanos e não-humanos. Na leitura de Lemos (2020) a respeito dessa noção de mediação do autor supracitado, o adjetivo radical enfatiza a mediação que envolve humanos e não humanos, e demarca, desse modo, a dimensão híbrida e materialista do seu entendimento. Tal noção é importante para o estudo do caso do Masterplano em razão das experiências inauguradas pela ambiência da plataforma Shotgun, que diferem das mediações que ocorrem nas pistas de danças dos espaços físicos e podem criar fluxos de informações, tensões e formas de representação que extrapolam as práticas nas interações presenciais.

O contexto da pandemia de COVID-19 transforma essas experiências. O que antes era mediado entre virtualidade e fisicalidade, agora é mediado exclusivamente por plataformas como a Shotgun, gerando possibilidades de experiências ainda desconhecidas, e também a reconfiguração dessas práticas em um possível retorno pós-pandemia, com atividades presenciais. Assim, a noção de mediação discutida por Grusin (2015) mostra-se relevante e adequada para esse estudo, como pode ser constatado a seguir:

$\mathrm{Eu}$ vejo as mediações gerando, remodelando e transformando experiências. (...) A mediação radical também insiste em um imediatismo que transforma, modula ou perturba relações vividas. (...) (GRUSIN, 2015, p.128). Para entender a mediação radical como afetiva e experiencial, em vez de estritamente visual, é importante pensar sobre nossa experiência afetiva imediata de mediação como aquilo que é sentido, corporificado, próximo - não distante de nós, e, portanto, não iluminada ou retratada, mas vivenciada por nós como viva, 
incorporando criaturas humanas e não-humanas. (GRUSIN, 2015, p.132) ${ }^{14}$.

Neste artigo, o que nos interessa é compreender como essas transformações das mediações remodelam a interação desta comunidade. De 2015 até hoje, as redes de mediações se estendem em diferentes plataformas, e, com a chegada do Shotgun Disdancing, essas redes do coletivo são ampliadas, reconfigurando, assim, a produção de conhecimento, dos fluxos de informações e experiências da comunidade.

Segundo Tristan Le Corre (2020), um dos idealizadores da plataforma Shotgun Disdancing, ainda que as transmissões sejam disponibilizadas futuramente no mesmo link, as conversas, os chats públicos e privados e imagens de webcam dos usuários são disponibilizados somente na transmissão ao vivo. Para o idealizador dessa plataforma, é importante definir uma lógica efêmera nessa ambiência, de modo que a festa não deixe nenhum vestígio além das memórias de seus participantes. Segundo ele, não são guardados históricos de bate-papo e nem de vídeos para que o que acontece na Shotgun permaneça na Shotgun. (LE CORRE, 2020). Não deixando vestígios dessas interações, elas só existiram naquele momento passado, e, no futuro, em um próximo evento online, serão novas interações, diferentes das lives do Youtube, por exemplo, que um usuário pode assistir às gravações e interações das transmissões em momentos posteriores à sua realização.

Quando a Shotgun foi pensada como plataforma de festas online seus idealizadores tiveram como base o trinômio temporalidade, materialidade e sociabilidade. Com base nisso, eles decidiram trabalhar uma nova forma de fazer evento, a partir de quatro eixos principais:

1- Resolver o problema da singularidade temporal, em particular para redescobrir a excitação do efêmero. 2- Resolver o problema da unidade espacial: visualmente, mentalmente, emocionalmente. 3- Tentar materializar ou mesmo aumentar dez vezes a intensidade das interações, emoções e intenções características de eventos festivos. 4-

\footnotetext{
${ }^{14}$ No original, em inglês: I see mediations as generating, refashioning, and transforming experiences (...) radical mediation also insists upon an immediacy that transforms, modulates, or disrupts experienced relations. (GRUISIN, 2015, p.128). (...) To understand radical mediation as affective and experiential rather than strictly visual is to think about our immediate affective experience of mediation as that which is felt, embodied, near - not distant from us, and thus not illuminated or pictured, but experienced by us as living, embodied human and nonhuman creatures. (GRUSIN, 2015, p.132)
} 
Permitir que várias identidades e comportamentos se expressem. (LE CORRE, 2020) ${ }^{15}$.

Neste trecho do texto, Le Corre (2020) salienta alguns aspectos que nortearam a criação da plataforma e o seu desejo por intensificar as interações e uso das affordances na plataforma. A partir desses eixos apresentados, identificamos as correlações do design da ambiência com as seguintes affordances: 1 - a supervalorização do ao vivo através dos chats, wall of fame e botão vermelho de identificação do ao vivo, 2 - os espaços virtuais que simulam pistas de dança, salas de dança e banheiros, 3 - os chats públicos e privados com texto, imagem e voz e 4 - a possibilidade do usuário criar chats privados, com senha, reforçando a identidade de um grupo de amigos ou comunidade.

Vale ressaltar que o vínculo entre o Masterplano e a Shotgun nasceu em abril de 2020, quando o coletivo artístico, insatisfeito com as funcionalidades das plataformas de streaming já conhecidas, começou uma intensa pesquisa até definir a utilização dessa plataforma em uma festa brasileira. Após apresentar a plataforma para o grupo e diversas reuniões com a equipe da Shotgun, foi agendada a festa Masterplano em Chromakeyla Tour para o dia 27 de junho de 2020.

Para criar um evento na plataforma é necessário preencher um formulário e responder a algumas perguntas de um representante da empresa para que a dinâmica e a identidade de determinado evento e da sua comunidade sejam registradas. A partir disso são desenvolvidas a customização da interface, formatação da identidade e outros. O link de acesso a uma festa do Shotgun Disdancing, apesar de disponibilizado um dia antes do evento, não funciona como link de divulgação. Toda a divulgação prévia da festa acontece em outras plataformas, como Facebook e Instagram. Porém, um dia antes do evento, quando o link da transmissão foi disponibilizado ao público, alguns usuários acessaram a plataforma pela primeira vez e deixaram ali seus primeiros rastros - mensagens no chat público, passeios pelo banheiro e até mesmo criação das primeiras salas públicas e privadas.

\footnotetext{
${ }^{15}$ Résoudre le problème d'unicité temporelle pour notamment retrouver l'excitation de l'éphémère. Résoudre la problématique d'unité spatiale: visuellement, mentalement, émotionnellement. Tenter de matérialiser voire de décupler l'intensité des interactions, émotions et intentions caractéristiques des événements festifs. Permettre aux multiples identités et comportements de pouvoir s'exprimer (LE CORRE, 2020).
} 
Para conhecer melhor a plataforma, serão descritas, a seguir, suas funcionalidades, possibilidades de interação e especificidades. Acionamos o conceito de affordance para compreender melhor as possibilidades de interagir e experimentar a ambiência de festa criada na plataforma. A noção de affordance foi desenvolvida por James Jerome Gibson, pesquisador da psicologia da percepção, nos anos 1970. Depois disso, o conceito foi discutido por diversos autores de diferentes áreas do conhecimento, como Hutchby (2017) que considera que as "affordances são as possibilidades que elas oferecem para a ação (...)" (HUTCHBY, 2017, p.7)" ou "o que fazem fazer" pelo modo como os objetos de uma interface convidam o usuário a agir. Para Lievrouw (2014), "as affordances podem ser vistas como os "usos potenciais" de um objeto" (LIEVROUW, 2014, p.48) ${ }^{16}$. No contexto de plataformização, as affordances são as possibilidades de deixar rastros e gerar dados em um fluxo contínuo de interações entre actantes humanos e não-humanos nos agenciamentos entre sistemas e usuários na plataforma.

\section{Shotgun e suas affordances: constituindo ambiências}

Até 2020, a Shotgun funcionava como um guia cultural online e sistema de venda de ingressos de shows, festas e eventos de música, boates, espetáculos e teatro na França. Em março desse mesmo ano, em virtude da pandemia, a marca se viu diante do desafio de criar eventos imersivos online e ampliar seus negócios. Da situação pandêmica, surgiu uma imensa frustração coletiva em razão da impossibilidade de realização de eventos e privação do convívio social. Dessa insatisfação, nasceu também um desejo da empresa por novos modelos de negócios, já que eventos físicos e, consequentemente, a venda de ingressos, não aconteceriam no momento de isolamento social. "Na Shotgun, quando o confinamento começou, tivemos uma sensação estranha: sentir que éramos a antítese do período atual” (LE CORRE, 2020). Esse trecho foi extraído do texto Une vision de l'événementiel après le confinement, publicado por Tristan Le Corre (2020) na plataforma Medium, após o lançamento da plataforma Shotgun Disdacing, em março de 2020.

Nesse texto, o programador enfatiza uma tríade que rege um evento festivo: a temporalidade (o tempo passa pelo evento), a materialidade (investimento e texturas sensoriais) e a sociabilidade (evento como uma comunidade efêmera), com o propósito

16 "Affordances can be seen as the "potential uses" of an object" (LIEVROUW, 2014, p.48). 
de gerar uma gama de sensações. Segundo Tristan Le Corre (2020), os usuários saem para uma festa, seguindo quatro critérios: 1 - os artistas da programação, 2 - a atmosfera (tipo de lugar, número de participantes, estilos de música), 3 - Valores (LGBTQIA+, inclusivo, paz, euforia) e 4 - Qualidade de som (sistemas de som, configurações etc.). Esses quatro critérios nortearam a criação da interface e programação da plataforma Disdancing.

\begin{abstract}
Além disso, existe toda uma gama de interações de baixa densidade, sentidas, mas invisíveis, interações simples na vida real, que se tornam complicadas, impossíveis no mundo virtual. Essas são as interações da intencionalidade, do humor: digamos que respiramos por cinco minutos, que vamos ao banheiro, que estamos cansados, que vamos tomar um drink ... um piscar de olhos, uma piada particular ou um flerte dentro de um grupo ... são interações simples, instantâneas, efêmeras, mas estruturantes para o grupo. (LE CORRE, 2020) ${ }^{17}$
\end{abstract}

As interações de baixa densidade, conceito criado pelo próprio programador da plataforma, seriam as interações invisíveis, não perceptíveis, discretas na ação dos humanos nos espaços, porém quase impossíveis em ambientes online, mas que fazem parte da dinâmica social de uma comunidade. Seguindo esses critérios, foi pensada e criada a plataforma Disdancing, uma experiência hipersensorial que envolve "sala, um chão, paredes, uma porta de entrada, luzes, cheiros” (LE CORRE, 2020,) ${ }^{18}$ e a sociabilidade de uma comunidade efêmera.

Para entender melhor o funcionamento da plataforma Disdancing, iremos compreendê-la com base nos seus principais recursos e affordances: 1 - monetização, 2 - salas de dança com vídeo, 3 - wall of fame, 4 - chat público, 5 - pistas de dança e 6 - banheiro. Quando um evento é criado na plataforma, é possível escolher o modelo de ingresso dos usuários. Isso implica no modelo de negócio que ele tem, o tipo de público, e se haverá ou não ingresso pago. Caso ele tenha um evento gratuito, ele poderá escolher o tipo de ingresso deste usuário, se será a partir de um login específico (quando o usuário faz o login com sua conta de Facebook, por exemplo, e aceita

\footnotetext{
${ }_{17}$ No original, em francês: Par ailleurs, il existe toute une palette d'interactions à faible densité, ressenties mais invisibles, des interactions simples dans la vie réelle, qui deviennent compliquées, impossibles dans le monde virtuel. Ce sont les interactions d'intentionnalité, de mood: dire qu'on s'aère 5 minutes, qu'on va aux toilettes, qu'on est fatigué, qu'on va chercher à boire... un clin d'oeil, une private joke ou un flirt au sein d'un groupe... Ce sont des interactions simples, instantanées, éphémères, mais structurantes pour le groupe (LE CORRE, 2020).

${ }_{18}$ No original, em francês: L'événement est une salle, un floor, des murs, une porte d'entrée, des lumières, des odeurs... (LE CORRE, 2020).
} 
compartilhar cookies) ou se o link estará aberto ao público sem a necessidade de login. Tudo isso implica na captura de dados e seu uso para futuras recomendações, personalizações e monetização, conforme a lógica da plataformização. No caso do evento Masterplano em Chromakeyla Tour, objeto de análise desse artigo, o evento foi aberto ao público, sem necessidade de login, e com uma aba Doações aberta ao público para uma doação financeira voluntária.

Para descrever melhor as funcionalidades e affordances desta plataforma, apresentaremos figuras focadas em cada função. Este material foi disponibilizado pela própria plataforma em um evento piloto, e as pessoas retratadas nestas figuras concederam o direito de uso de imagem para a marca Shotgun. As salas de dança são criadas pelo público ou previamente pelos produtores da festa para incentivar a interação via chat de texto, áudio de microfone e imagem de webcam. As salas podem ser públicas ou privadas. As salas privadas têm acesso com senha definida pelo seu criador e distribuída para seus amigos mais próximos.

Figura 1 - Salas de dança em um evento piloto no Shotgun Disdancing

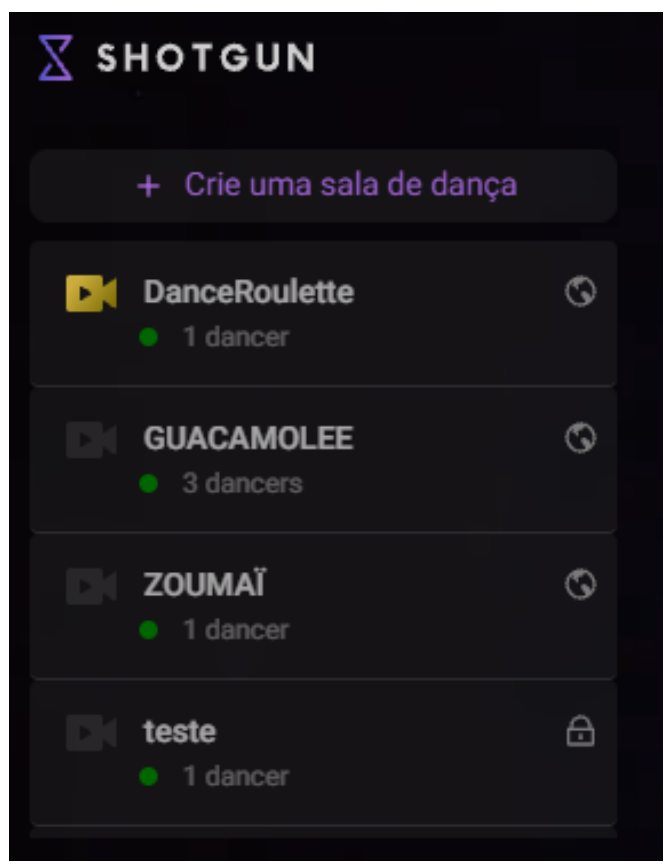

Fonte: Página do Shotgun live (2021).

O wall of fame é uma affordance de compartilhamento de vídeo randômico. O usuário presente pode ativar um botão no canto direito da plataforma para que, em um momento aleatório da festa, sua webcam seja ativada e uma gravação de 15 segundos 
seja feita e, posteriormente, compartilhada para todos os usuários presentes na plataforma.

\section{Figura 2 - Wall of fame no Shotgun Disdancing}

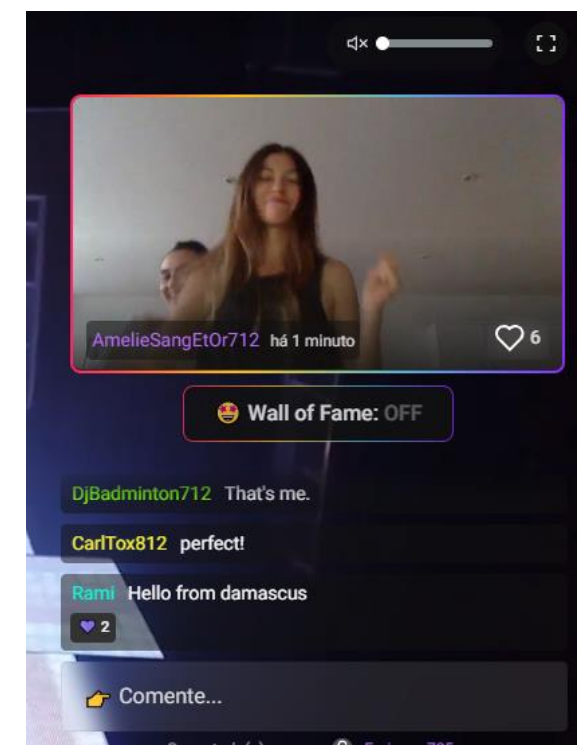

Fonte: Página do Shotgun live (2021).

O chat público é a affordance de troca de mensagens de texto para todo o público da festa online. Ao abrir o chat pela primeira vez, o usuário ganha um nome randômico escolhido pela própria plataforma. Os nomes aleatórios geralmente são nomes de DJs e músicos mundialmente famosos, como Madonna, David Guetta, Honey Dijon etc. Para editar o seu próprio nome, o usuário deve fazer um login no Facebook pela própria plataforma e aceitar os termos de usuário.

Figura 3 - Chat público no Shotgun Disdancing

ManoLeToug91 my gooood

ILoveModels191 what year did u graduate

DjKozeBcoup936 lol what's my ID??

\section{LenTapis470 Saxxy-time!}

E.

- Comente..

Fonte: Página do Shotgun live (2021). 
As pistas de dança são os locais onde as transmissões dos DJs, músicos, performers e artistas visuais acontecem. Várias pistas de dança podem acontecer simultaneamente no mesmo evento, explorando diferentes atmosferas, gêneros musicais e tipos de atividades. Exemplo: em dezembro de 2020, o coletivo Masterplano realizou, em formato online, o Festival Clubbers da Esquina. Além de shows de bandas musicais, apresentação de DJs e artistas visuais, aconteceram também debates no Disdancing.

\section{Figura 4 - Pistas de dança no Shotgun Disdancing}

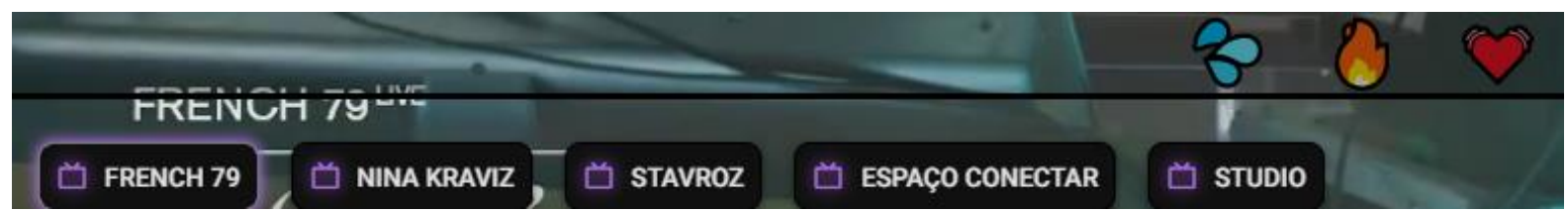

Fonte: Página do Shotgun live

Uma festa presencial é feita por diferentes espacialidades e o banheiro é uma delas. Para incentivar interações movidas por outros sentidos, nesta plataforma há também um banheiro público. Neste espaço, há a possibilidade de o usuário conversar por chat de texto e intervir no layout do banheiro com um emoji, desenhar, rasurar ou escrever algo de sua livre escolha. Neste espaço, não há a possibilidade de interagir por webcam ou por áudio de microfone.

\section{Figura 5 - Banheiro no Shotgun Disdancing}

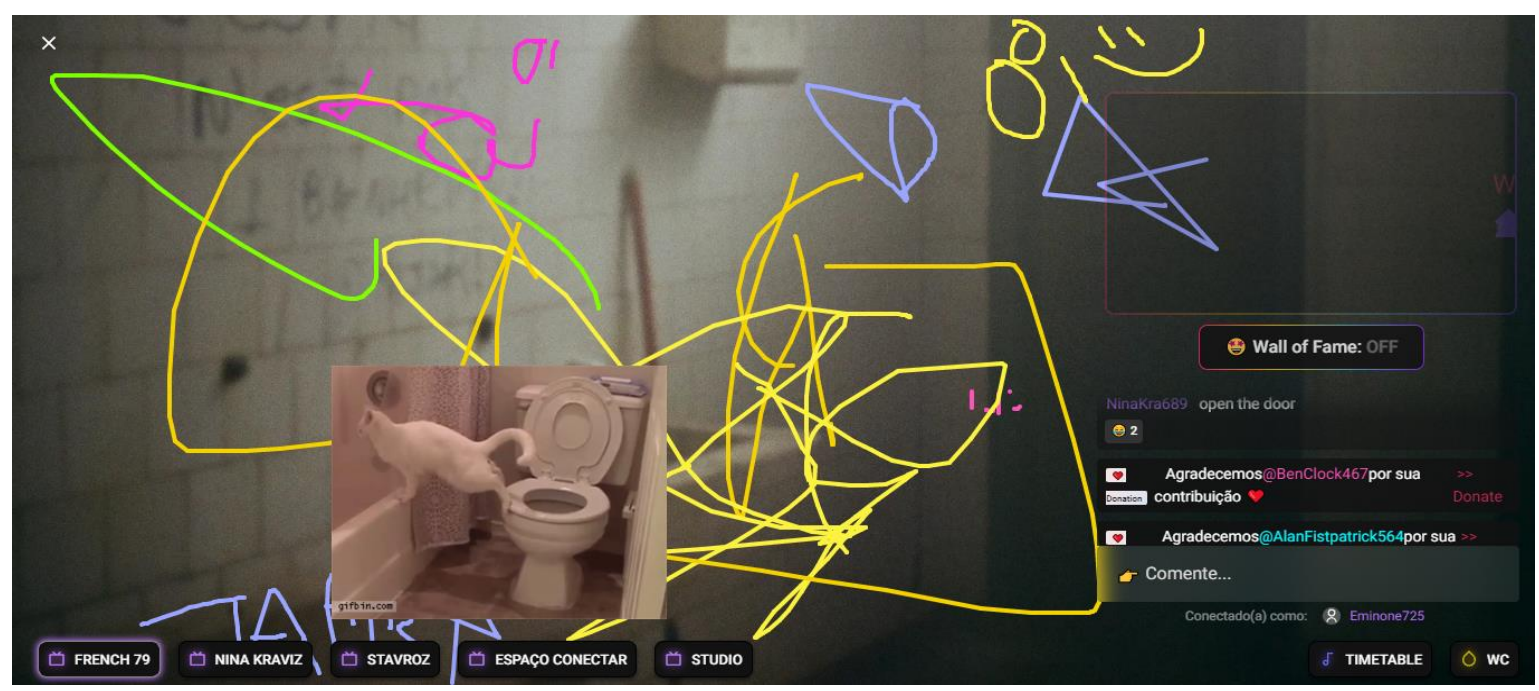

Fonte: Página do Shotgun live (2021). 
Durante a festa online, os usuários também podem reagir/clicar em emojis pequenas representações em ilustração utilizadas em grande escala em teclados e conversas online. Os emojis são escolhidos pelos produtores do evento na fase de contratação do serviço Shotgun. Esse tipo de reação com emojis está disponível em qualquer parte da interface, exceto no banheiro.

\section{Figura 6 - Reação com emojis no Shotgun Disdancing}

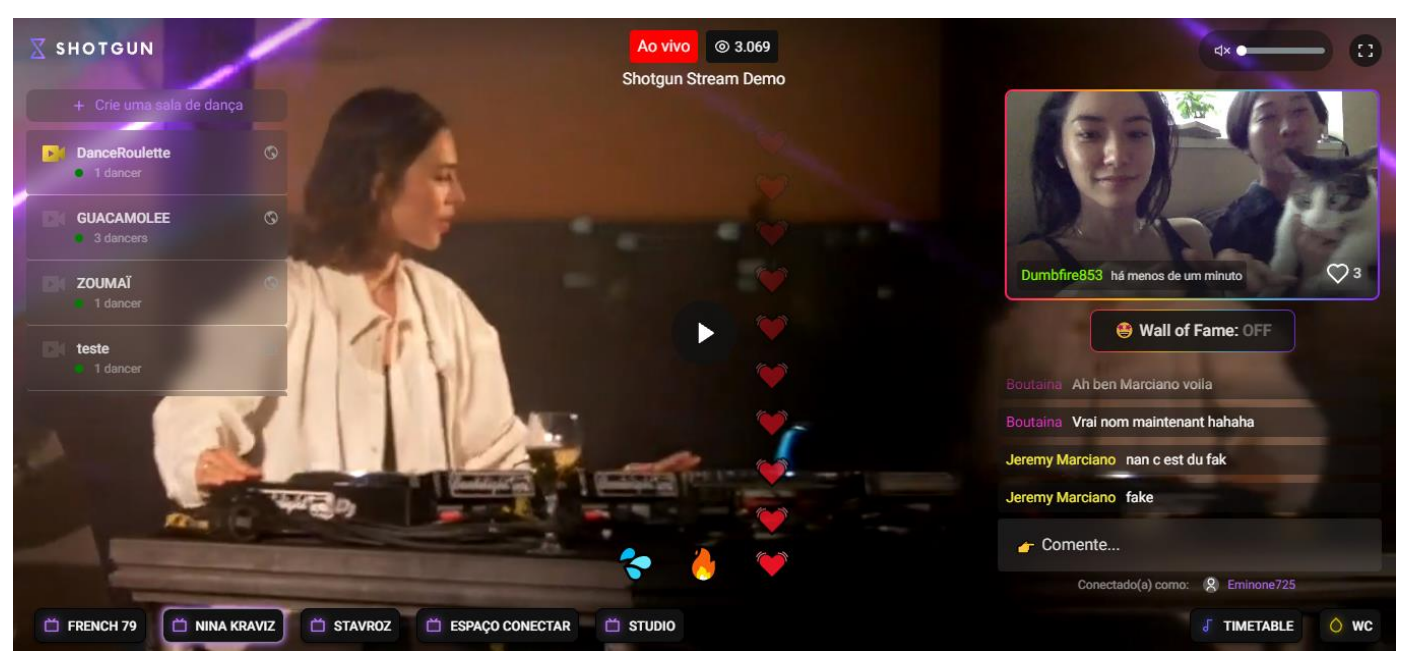

Fonte: Página do Shotgun live (2021).

Para o público se orientar sobre os artistas e a programação das festas, há uma função denominada timetable, no canto direito da interface, onde consta a programação completa. Timetable é uma expressão usada em eventos de música eletrônica, e se refere à ordem cronológica em que os artistas, músicos, DJs e performers se apresentarão em um evento. 


\section{Figura 7 - Timetable (programação de artistas) no Shotgun Disdacing}

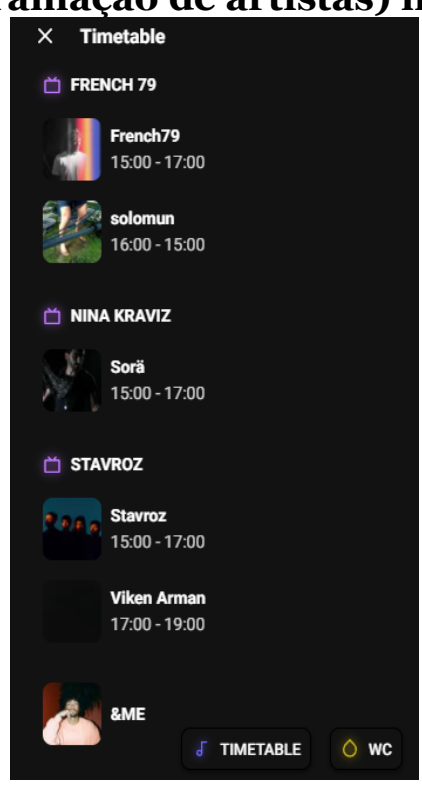

Fonte: Página do Shotgun live (2021).

Importante frisar que, em qualquer desses espaços visitados, a música da pista de dança (escolhida pelo usuário) não cessa. Os espaços virtuais são visitados, mas a atmosfera sonora da festa é experienciada durante toda a jornada do usuário, dentro da mesma plataforma.

\section{Figura 8 - Página inicial de um evento no Shotgun}

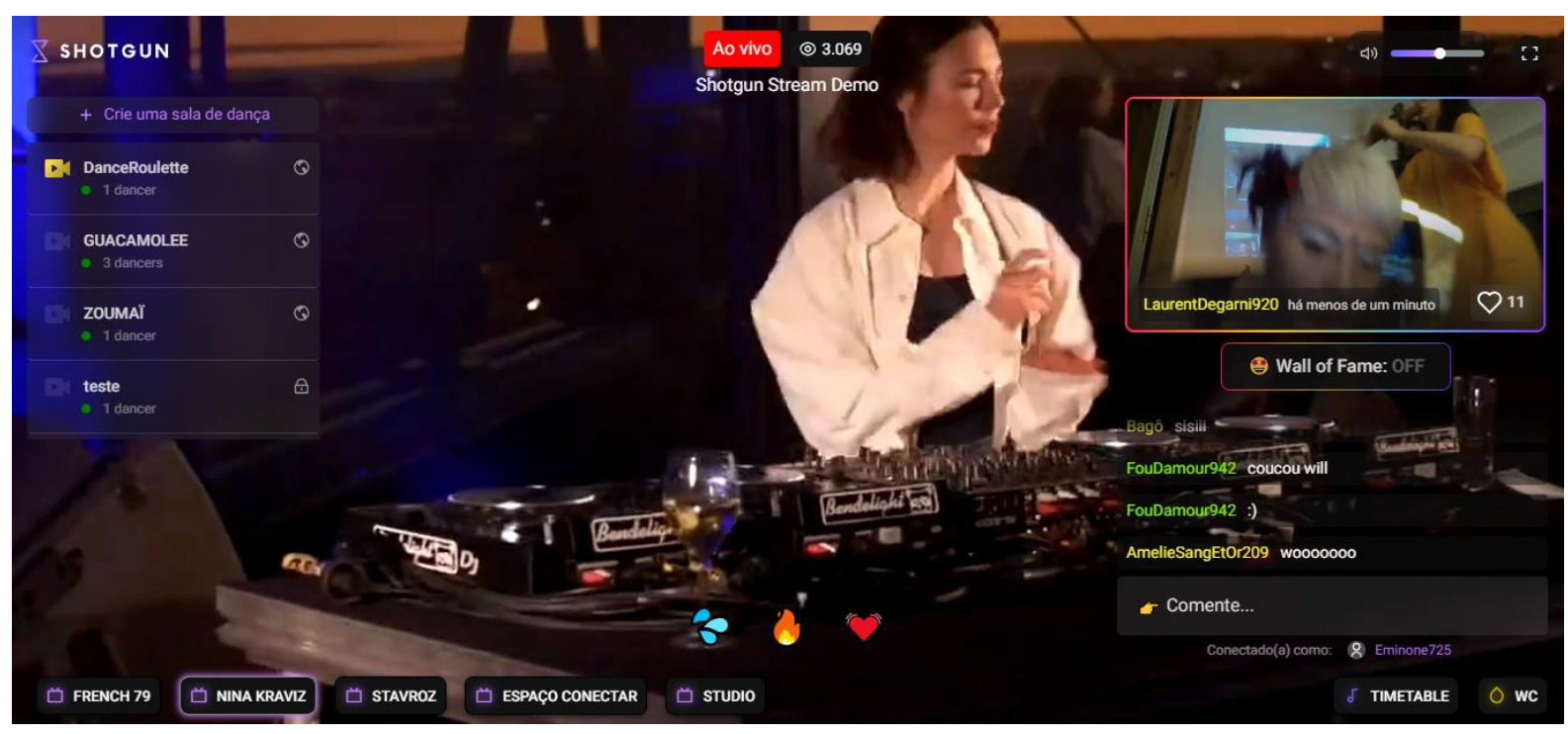

Fonte: Página do Shotgun live 


\section{Masterplano em Chromakeyla Tour}

Para a consecução do objetivo proposto nesse artigo, recorremos aos métodos digitais e à observação participante para a coleta e análise de dados. Entende-se que tais métodos permitem usar rastros digitais para estudar não apenas os fenômenos online, mas também a cultura e a sociedade em geral (ROGERS, 2013). Assim, entendemos que reaproveitar a mídia significa usar rastros digitais para compreender fenômenos que se estendem além desses rastros (VENTURINI; BOUNEGRU; GRAY, 2018) ${ }^{19}$, como a interação da comunidade Masterplano mediada pela plataforma Shotgun.

Registramos os percursos nas affordances distribuídas a partir de observação em contextos de reuniões do coletivo, divulgação do evento, interação com os usuários online, elaboração de material tutorial para o uso da plataforma e participação como $D J$ e usuário da plataforma durante o evento Masterplano em Chromakeyla Tour, que ocorreu no dia 27 de junho de 2020. Além disso, a observação participante se estendeu também para outras festas online realizadas na mesma plataforma, tais como Plano 3 anos (25 de julho de 2020), Mamba Negra O Kulto (7 de agosto de 2020) e Festival Clubbers da Esquina ( $1^{\circ}$ a 13 de dezembro de 2020). As análises das affordances foram desenvolvidas com base nas informações disponibilizadas pelo programador e criador da Shotgun Disdancing, Tristan Le Corre, breves conversas via Whatsapp com a equipe Shotgun Brasil e descrição das funcionalidades da plataforma. Essas etapas aconteceram no período de junho de 2020 a setembro de 2021.

O evento online Masterplano em Chromakeyla Tour no Disdancing da plataforma Shotgun durou 12 horas e teve aproximadamente 2.900 pessoas, 127 mil minutos de transmissão, 9.284 mensagens trocadas, 125 salas de dança criadas, 1.700 visitas ao banheiro, mais de 2.700 cliques na timetable, 957 câmeras abertas no wall of fame e uma média de 43 minutos de presença por usuário, números relativamente expressivos para festas online.

A festa começou às 22h, com uma breve apresentação de um dos integrantes do coletivo, via webcam e microfone. $D J$ Supololo recebeu os convidados, lendo um texto curto, apresentando a programação da noite, os patrocinadores, como funcionariam as pistas de dança e incentivando o uso massivo de todas as funcionalidades da

\footnotetext{
19 "Repurposing the media means using digital traces as proxies for phenomena that extend beyond them" (VENTURINI; BOUNEGRU; GRAY, 2018, p.7).
} 
plataforma, que, até então, eram uma novidade para a comunidade. Nesse momento, o chat público já estava com alto número de mensagens, evidenciando a euforia dos usuários e o motivo do encontro: a festa de aniversário do Masterplano, o coletivo artístico.

Para a coleta de dados, o acesso à festa foi realizado via login utilizando conta pessoal de Facebook, confirmação e aceite de cookies a fim de interagir utilizando o nome pessoal na festa. A observação foi feita a partir de uma permanência de aproximadamente oito horas, acessando todas as funcionalidades e affordances apresentadas nos tópicos anteriores. A partir de uma observação participante desta cena de música eletrônica e de festas eletrônicas online, consideramos números relevantes para eventos neste formato.

O percurso das affordances se deu em maior parte pelas pistas de dança, salas de dança, chat público, wall of fame e banheiro. As interações de baixa densidade, como descritas pelo programador, ganharam força, o que foi observado pelo número de mensagens trocadas - 9.284 e a média de presença por usuários: 43 minutos. Em campo, as interações de baixa densidade foram observadas principalmente pela criação de grupos pequenos e fechados, como amigos que queriam compartilhar uma fofoca, uma opinião privada sobre aquele ou outro $D J$ e artista que se apresentava na transmissão, ou até mesmo, um flerte no chat público, que trazia uma euforia coletiva por parte de muitos usuários. Além disso, as câmeras abertas no wall of fame, affordance de compartilhamento de vídeo randômico, somaram 957 imagens, que eram compartilhadas para qualquer usuário presente na plataforma. A plataforma não disponibilizou o número de microfones abertos na festa Masterplano em Chromakeyla Tour, porém foi observado que muitos usuários preferiram não utilizar esse recurso para evitar confusão na escuta das fontes sonoras da apresentação de $D J s$ e microfones.

A experiência na Shotgun Disdancing perturbava e transformava as relações vividas anteriormente, agora que a comunidade em questão estava mediada por uma plataforma com affordances e funcionalidades próprias, em uma temporalidade específica. Durante o evento, por exemplo, o banheiro era um ponto de reunião onde alguns usuários compartilhavam experiências, com o uso de entorpecentes e bebida alcóolica. Neste espaço específico, não é possível compartilhar imagem de webcam e microfone, há somente um chat de texto, o que garante ainda aos usuários certa privacidade e liberdade para conversas sobre temas sensíveis. 
Algo que percebemos também na observação participante foi um aspecto sobre a definição dos nomes das salas de dança criadas, tanto as públicas quanto as privadas, que foram nomeadas com tags que exaltavam uma identificação direta com os grupos que compõem esta cena nas festas físicas como, por exemplo, \#SAPATAO20oo, \#CLUBBERSDAESQUINA, \#FRONT, e outras.

A dinâmica social de uma fila ou a saída para a compra de um ingresso, antes da festa, foi ressignificada a partir da representação nas interfaces dessa plataforma. Percebia-se ali já uma variedade de interações, apropriações das ambiências e descoberta dos usos das affordances disponíveis. Muitas vezes, os usuários usavam o chat público para perguntar como alterar o nome do usuário, como ligar a câmera e como mudar de pista de dança.

Durante a festa, as espacialidades da plataforma foram exploradas. Um usuário mudava de pista de dança caso a música ali não lhe seduzisse, e, no banheiro, usuários compartilhavam suas contas de Instagram para manter contato futuro. Em algumas salas de dança, pessoas conversavam sobre temas gerais como cotidiano, política, como enfrentavam a pandemia e o isolamento social, sem deixar de ouvir a música tocada pelo $D J$, que não cessava. As representações de affordances também não pareciam tão intuitivas, como, por exemplo, a diferenciação das pistas de dança (onde os artistas se apresentam) e salas de dança (onde os usuários interagem em grupos fechados ou abertos). A representação da affordance do banheiro era a mais intuitiva, tanto pela sigla $W C$ quanto pela interface da espacialidade com imagens de banheiro, vasos sanitários e a opção de pichações (uma prática comum em banheiros públicos). Nas pichações, assim como na prática social de banheiros públicos, lia-se nomes, telefones e representações visuais de genitálias.

Outro fator importante desta experiência é que a comunidade Masterplano, antes restrita a residentes em Belo Horizonte, foi estendida para públicos fora dessa cidade, o que demonstra uma ampliação das redes de mediação e da própria comunidade. Observamos que, também por isso, esta comunidade se ressignifica mediante a inserção de novos códigos e práticas de outros contextos ao associar redes e outras comunidades eletrônicas do Brasil e do mundo.

\section{Considerações finais}

Neste artigo foram adotadas como estratégias de coleta e análise de dados pesquisas descritivas e exploratórias juntamente à observação participante para 
compreender as redes delineadas em torno do coletivo Masterplano, que incluiu a plataforma Shotgun Disdancing em sua rede multiplataforma. A partir do entendimento da mediação radical neste processo e das affordances distribuídas nas interfaces para constituição da ambiência da festa, observamos que os elementos festa eletrônica, interações na pista de dança e entretenimento são representados por novos objetos a partir da mediação da plataforma. Essa relação reflete a virada materialista ou virada não-humana, ressaltando a agência dos objetos, suas performances como mediadores e seus modos específicos de afetação, como discute Lemos (2020).

A noção de comunidade é ampliada, incluindo quem está online e participa de outras comunidades eletrônicas pelo mundo, gerando possibilidades de reconfiguração contínua das interações sociais, produção de conhecimento, difusão de cenas musicais variadas e envolvimento de novos grupos. A música eletrônica no Brasil e no mundo têm vertentes diversas e, com o contexto de plataformização, essas produções passam a ser conhecidas e amplificadas, apesar da super capitalização dos dados.

Esperamos que este estudo sirva de base para pensarmos o futuro de coletivos juvenis como esses em um contexto pós-pandemia. O entretenimento, a festa, e a música eletrônica de pista, que antes pareciam ser a antítese do isolamento social, ganham novas feições com a constituição dessas ambiências em plataformas a exemplo da Shotgun, possibilitando a emergência de novos espaços e temporalidades junto das comunidades que vivem e festejam em pistas de dança em espaços físicos e plataformas online.

\section{Referências Bibliográficas}

ASSEF, Claudia. Capslock faz 8 anos de resistência, line-up do aniversário está incrível. Uol Urban Taste - 16 de janeiro de 2019. Disponível em: <https://cutt.ly/VfcULq8>. Acesso em 15 jun.2021.

BUZATTI, Lucas. Muito além do tux-tux: coletivos reinventam a cena eletrônica de BH. Hoje em Dia, Belo Horizonte, 21 de outubro de 2017. Disponível em $<$ https://cutt.ly/2flhXMf >. Acesso em 15 jun.2021.

FERREIRA, Pedro Peixoto. Transe Maquínico: quando som e movimento se encontram na música eletrônica de pista. Horizontes Antropológicos, Porto Alegre, ano 14, n. 29, p. 189-215, jan./jun de 2008. Disponível em: <https://cutt.ly/XflhC8r >. Acesso em 15 jun.2021. 
GRUSIN, Richard. Radical Mediation. In: Critical Inquiry. The University of Chigaco Press. Vol.42, No.1 (Autumm 2015), pp.124-148.

HUTCHBY, Ian. "Technology, Texts, and Affordances." Sociology. May 2001 vol. 35 no. 2. $441-456$

LANGLOIS, Ganaele. Meaning in the age of Social Media. Palgrave Macmillan. New York, NY, 2014.

LATOUR, Bruno. Reagregando o Social: uma introdução à teoria do Ator-Rede. Salvador: Edufba, 2012; Bauru, São Paulo:Edusc, 2012.

LE CORRE, Tristan. Pourquoi événements et streaming sont incompatibles.

Medium - 19 de junho de 2020. Disponível em: < https://bit.ly/3drIvVF > . Acesso em 7 dez. 2021.

Tristan. Une vision de l'événementiel après le confinement. Medium - 14 de junho de 2020. Disponível em: <https://cutt.ly/RnKH5wW>. Acesso em 15 jun.2021.

LEMOS, André. Epistemologia da comunicação, neomaterialismo e cultura digital. GALÁXIA (SÃO PAULO. ONLINE), v. 43, p. 54-66, 2020.

LIEVROUW, Leah A. Materiality and Media in Communication and Technology Studies: An Unfinished Project. In: Materiality and Media in Communication and Technology Studies: An Unfinished Project. In: Media Technologies: essays on Communication, Materiality and Society.The MIT Press. Cambridge, Massachusetts. London, England, 2014.

PEREIRA, Simone Luci; GHEIRART, Oziel. Caminhos da cena de música eletrônica em festas de rua em SP: estéticas, territórios e ativismos na festa e no personagem CARLOS CAPSLOCK. Comunicação \& Inovação, PPGCOM/USCS - v.21, n.45 [03-21] jan-abr 2020.

PASQUINELLI, Matteo; JOLER, Vladan. The Nooscope Manifested: Artificial Intelligence as Instrument of Knowledge Extractivism. KIM research group (Karlsruhe University of Arts and Design) and Share Lab (Novi Sad), 1 May 2020 (preprint forthcoming for AI and Society). Disponível em: http://matteopasquinelli.com/nooscope/ Acesso em: 16. Mar. 2021

ROGERS, Richard. Digital Methods. Cambridge: The MIT Press, 2013.

VAN DIJCK, José Van.; POELL, Thomas.; DE WAAL, Martijn. The platform society: Public values in a connective world. Oxford: Oxford University Press, 2018.

VENTURINI, Tommaso., BOUNEGRU, Liliana., GRAY, Jonathan., \& ROGERS, Richard. (2018). A reality check(list) for digital methods. New Media \& Society, (forthcoming), 146144481876923. http://doi.org/10.1177/1461444818769236

Este é um ARTIGO publicado em acesso aberto (Open Access) sob a licença Creative Commons Attribution, que permite uso, distribuição e reprodução em qualquer meio, sem restrições, desde que o trabalho original seja corretamente citado. 